\title{
Evaluation of ultra-short dialysis
}

\author{
J A P TRAFFORD, P SHARPSTONE, R EVANS, R IRELAND
}

British Medical fournal, 1979, 1, 518-519

\section{Summary and conclusions}

A study was carried out to compare the effects of three dialysis regimens of different durations. Nineteen patients dialysed over 1975-7 for an average of only 11.2 hours per week were compared with nine dialysed for 24 hours per week (1974-6) and 10 dialysed for 27 hours (1971-3). Clinical, biochemical, and haematological results showed that the short dialysis regimen was as effective as the longer regimens, except that patients had to take a phosphate binder regularly, and that it was considerably cheaper.

Short dialysis has social and economic benefits, since patients have more free time and more patients can be treated with the same number of staff and dialysis stations. As in many areas there is a shortage of places for patients needing dialysis, a short regimen is recommended.

\section{Introduction}

Haemodialysis is an effective treatment for end-stage renal failure. Though it does not correct all the metabolic abnormalities of uraemia, its overall clinical results are satisfactory. Since no single toxin has been identified as the cause of the uraemic syndrome, various biochemical markers have been used to judge the effectiveness of dialysis; ultimately, however, the clinical state of the patient decides this. Many techniques have been used with apparently similar clinical results despite the different models of dialyser, type and area of dialysis membrane, duration of dialysis, and dialysis flow rate. Thus the success or otherwise of dialysis depends on clinical assessment, and no agreement can be expected on the ideal dialysis regimen.

In 1974 Cambi et al ${ }^{1}$ showed that a shorter dialysis schedule than those used at the time gave good clinical results. In Brighton we progressively reduced the duration of dialysis from a weekly average of 27 hours in 1969 to $18-24$ in 1973, and since then we have operated a short dialysis of under 12 hours per week. At the beginning of 1975 the average duration of dialysis was reduced to $11 \cdot 16$ hours and in 1978 it was 9.6 hours. We report here details of 19 patients who completed three years of regular dialysis of under 12 hours per week and compare them with results obtained with the longer regimens of earlier years.

\section{Patients and methods}

The patients were dialysed on Travenol RSP machines, using a positive-pressure coil system. Heparinisation was with an initial injection of 7500 units, followed by injections of 2000 units when required. Access was by a Cimino fistula, and blood-flow rates

Renal Unit, Royal Sussex County Hospital, Brighton, Sussex BN2 5BE

J A P TRAFFORD, FRCP, consultant physician and director of renal unit P SHARPSTONE, FRCP, consultant physician

R EVANS, SRN, sister in charge

$R$ IRELAND, MB, BS, research fellow were $250-300 \mathrm{ml} / \mathrm{min}$. The rate of flow of dialysate was $400 \mathrm{ml} / \mathrm{min}$. All patients had creatinine clearances of less than $2 \mathrm{ml} / \mathrm{min}$ - that is, minimal residual renal function. Their nominal protein intake was $1 \mathrm{~g} / \mathrm{kg}$ body weight.

We compared three groups of patients. The first group comprised 10 patients dialysed with a 27-hour regimen (1971-3). The second group comprised nine patients, who continued to be dialysed but with a slightly shorter regimen (1974-6). The third group comprised 19 patients (including nine from the preceding group), who completed three full years on short dialysis (1975-7). Of these 19, nine have now completed more than seven years' dialysis and were common to all three groups. Patients who received kidney transplants are not reported here. Ten of the 19 patients were dialysed with an EX29 $1.4 \mathrm{~m}^{2}$ coil, six with a Travenol $1.4 \mathrm{~m}^{2}$ coil, and three smaller patients with an EX25 $1 \mathrm{~m}^{2}$ coil. The average duration of dialysis for the patients was $11 \cdot 16$ hours (range $8-14$ hours).

\section{Results}

Table I summarises the clinical evaluation in all the patients over the three periods. In the third group two patients had already had a subtotal parathyroidectomy but none had symptomatic bone disease. In 1977, however, 17 of the 19 still needed hypophosphataemic treatment with aluminium hydroxide. All underwent radiological surveys of the skull, hands, spine, and pelvis. Three showed changes of hyperparathyroidism with subperiosteal erosions in the phalanges. There were no pathological fractures. No patient had symptoms or stigmata of peripheral neuropathy, and the motor-nerve conduction velocity measured in the ulnar nerve from elbow to wrist was within the normal range in all. Only two were still taking antihypertensive treatment. Table II summarises the mean predialysis haematological and biochemical results for the last four weeks of each three-year period.

The rehabilitation of the patient was assessed with the six-point scoring method used by the EDTA Registration Committee.: Category 1 is applied to patients working full time and category 6 to patients requiring hospital care. The mean score of the 19 patients dialysed most recently was $1 \cdot 37,15$ of them being in category 1 .

TABLE I-Clinical evaluation of long and short dialysis

\begin{tabular}{|c|c|c|c|}
\hline & $\begin{array}{l}\text { Jan } 1971- \\
\text { Dec } 1973\end{array}$ & $\begin{array}{l}\text { Jan } 1974- \\
\text { Dec } 1976\end{array}$ & $\begin{array}{l}\text { Jan } 1975- \\
\text { Dec } 1977\end{array}$ \\
\hline $\begin{array}{l}\text { No of patients . } \ldots \\
\text { Duration of dialysis (hours week) } \\
\text { No of patients with radiological bone changes.. } \\
\text { Mean weight loss dialysis }(\mathrm{kg}) . . \\
\text { No of patients still taking antihypertensive drugs }\end{array}$ & $\begin{array}{c}10 \\
27 \\
2 \\
1 \cdot 5 \\
2\end{array}$ & $\begin{array}{c}9 \\
24 \\
2 \\
2 \cdot 0 \\
1\end{array}$ & $\begin{array}{l}19 \\
11 \cdot 16 \\
3 \\
1 \cdot 76 \\
2\end{array}$ \\
\hline
\end{tabular}

Note-No patients had neuropathy

TABLE II-Haematological and biochemical evaluation of long and short dialysis. Results are means of values obtained before dialysis for last four weeks of each three-year period

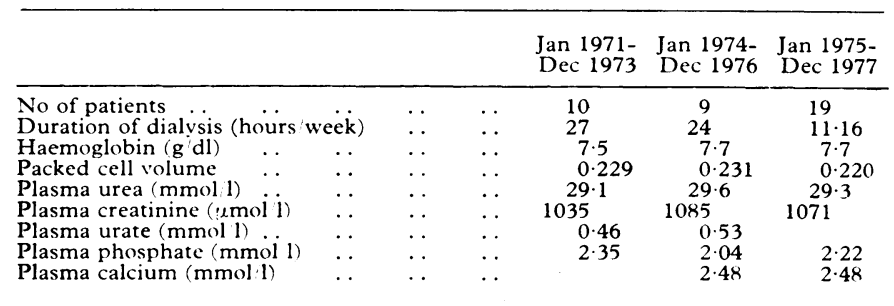

Conversion: SI units to traditional units-Urea: $1 \mathrm{mmol} \mathrm{1}=6 \mathrm{mg} 100 \mathrm{ml}$. Creatininc: $1 \mu \mathrm{mol} 1=0.01 \mathrm{mg} 100 \mathrm{ml}$. Urate: $1 \mathrm{mmol} 1=16.5 \mathrm{mg} 100 \mathrm{ml}$. Phosphate: $1 \mathrm{mmol}$ $\approx 3.2 \mathrm{mg} 100 \mathrm{ml}$. Calcium: $1 \mathrm{mmol} 1=4.0 \mathrm{mg} / 100 \mathrm{ml}$. 
The figure shows the cumulative survival for 86 patients who received haemodialysis during 1966-78. The five-year survival rate was $70^{\circ}$. Out of nine patients who have completed over five years on haemodialysis, none have died. Three patients have now completed 10 years on haemodialysis. Mortality in the first year on dialysis fell from $33^{\circ}{ }_{0}(1966-70)$ to $11^{\circ} \%(1974-8)$.

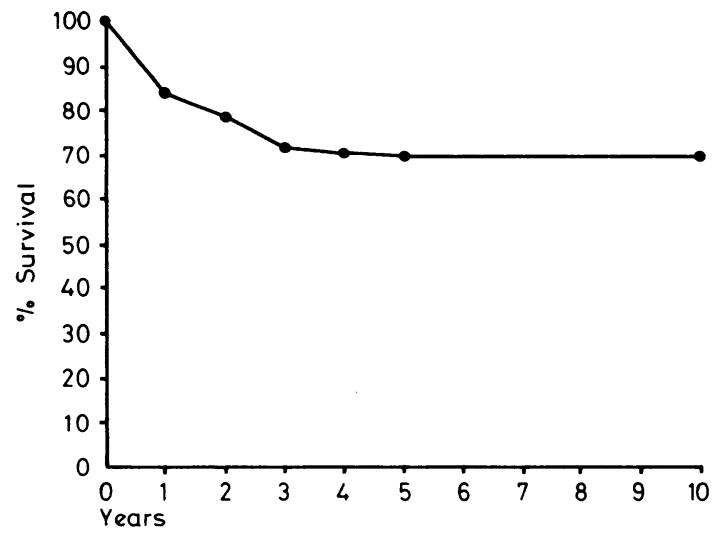

Cumulative patient survival related to number of years spent on dialysis (1966-78).

\section{Discussion}

For many years the efficiency of dialysis was measured in terms of the clearance from plasma of substances with small molecular weights, such as urea and creatinine. It was later shown that many complications of uraemia, such as neuropathy, could occur despite maintained low plasma concentrations of these substances. Conversely, patients could be clinically well with relatively high concentrations. The "middle molecule hypothesis" 3 was formulated to account for these discrepancies. It was postulated that substances of middle molecular weight (300-5000 daltons) accumulating in plasma were responsible for many of these manifestations and that substances with lower molecular weights were relatively harmless. Dialysis techniques that favour the clearance of middle-weight rather than small molecules produce satisfactory clinical results despite relatively high plasma concentrations of the more conventionally measured urea or creatinine. Earlier maintenance dialysis schedules used dialysers of low efficiency for as long as 30 hours per week. ${ }^{4}$ In 1973 Cambi et $a l^{5}$ showed that shortening the duration of dialysis did not result in impaired motor-nerve conduction, and in 1975 they showed ${ }^{1}$ that a schedule of four hours, three times a week or three hours on alternate days using a $1 \mathrm{~m}^{2}$ area dialyser, gave good clinical results in the short term. Subsequently others confirmed the success of short dialysis. ${ }^{6-8}$

Our results show that short dialysis, averaging $11 \cdot 16$ hours in the most recently studied 19 patients, yields results as satisfactory as those of long-dialysis schedules except in respect of the plasma phosphate concentrations; most patients needed to take a phosphate binder regularly. No clinical neuropathy or increase in bone disease occurred. Control of hypertension presented no difficulty. Most important, the patients preferred the short dialysis regimen, and the rehabilitation state of the patients was similar. Patients tolerated the more efficient dialysis (with more rapid fluid and "toxin" removal) well, though new patients were always initiated gently with frequent short dialyses at low blood-flow rates.

The figures for cumulative patient survival show that of all those that died, $54^{\circ}{ }_{0}$ did so in the first year on dialysis, and that the risk of death decreased with increased duration of dialysis. The mortality rate in the first year on dialysis decreased noticeably despite relaxed criteria for admission to the programme. Earlier haemodialysis, before clinical deterioration was pronounced, may in part have accounted for these improved results. There was no evidence to suggest that short dialysis adversely affected survival.

The social benefits of short dialysis are self-evident in that the patients spend less time on dialysis and consequently have greater freedom for other activities. The economic benefits are also evident, for with the same staff an extra shift may be operated, thus allowing an increased number of patients to be dialysed without any increase in the number of dialysis stations or staff. In December 1977 the Minister of Health stated that the annual cost of dialysis per patient in the UK averaged $£ 10000 .{ }^{9}$ In our unit, using short dialysis for a greater number of patients but with the same number of dialysis stations and staff, the costs are about $£ 7500$ per annum. Information collected from European dialysis centres by the EDTA Registration Committee $^{10}$ shows that during the past four years the average dialysis time throughout Europe has progressively shortened. During 1976 in Europe as a whole $31 \%$ of patients received less than 13 hours of dialysis and only $9 \%$ over 18 hours. By contrast, in the UK only $17 \%$ were receiving under 13 hours while $37 \%$ were still receiving more than 18 hours per week. Fewer than $3 \%$ were receiving under 10 hours, and our average for 1978 was 9.6 hours per week.

We believe that our results have shown no important drawbacks to short dialysis and several advantages. It would seem reasonable to recommend its wider adoption on the grounds of medical, economic, and social benefit. The equipment we used is available worldwide, and the technique is adaptable to any in current use. A shortage of places for dialysis patients still exists in many parts of the country, and using this short regimen could enable more patients to be dialysed more economically.

\section{References}

${ }^{1}$ Cambi, V, et al, Proceedings of the European Dialysis and Transplant Association, 1975, 11, 112

2 Gurland, $\mathrm{H} \mathrm{J}$, et al, Proceedings of the European Dialysis and Transplant Association, 1976, 13, 49.

${ }^{3}$ Babb, A L, et al, Transactions: American Society for Artificial Internal Organs, 1972, 18, 98.

${ }^{4}$ Curtis, J R, et al, Quarterly fournal of Medicine, 1969, 38, 49.

5 Cambi, V, et al, Proceedings of the European Dialysis and Transplant Association, 1973, 10, 271.

${ }^{6}$ Manji, T, et al, Proceedings of the European Dialysis and Transplant Association, 1976, 12, 589.

7 Shaldon, S, et al, Proceedings of the European Dialysis and Transplant Association, 1976, 12, 596.

${ }^{8}$ Alvarex-Ude, F, et al, Proceedings of the European Dialysis and Transplant Association, 1976, 12, 606.

${ }^{9}$ Hansard, House of Commons, 6 December 1977.

${ }_{10}$ Wing, A J, et al, Proceedings of the European Dialysis and Transplant Association. In press.

(Accepted 20 December 1978)

ONE HUNDRED YEARS AGO In the cobalt, bismuth, and nickel mines at Schneeberg, cancer of the lungs is, according to Dr W Hesse of Schwarzenberg (Archiv der Heilk, Heft ii, 1878, p 16), extremely frequent. The following is the proportion. Among 600 to 700 miners, there are from 28 to 32 deaths per annum, and of these deaths 21 to 24 are due to cancer of the lung. The disease is developed at about forty years of age, and especially among those who live poorly and are ill-nourished. From the point of view of causation, a special action has been attributed to the powder breathed in the atmospheric air in the interior of the galleries and to the frequent changes of temperature at the time when the workman, after laboriously mounting, reaches the surface of the soil. For the most part, the affection is at first latent; then intercostal pain shows itself, cough, sometimes pleurisy, pneumonia, spitting of blood, vomiting, etc; exhaustion and marasmus become well-marked; and death follows, sometimes with abundant hæmoptysis. On post mortem examination, according to Wagner, there are found cancerous nuclei, varying in size from a small nut to the fist, radiating from the hilum of the lung. The pleura is often invaded. The glands, blackened and pigmented, do not most frequently present any degeneration. (British Medical fournal, 1879.) 